diseases, including cholera. A recently infected victim who did not have any knowledge about cholera might take antacids or refrain from taking liquids - the worst possible management. At the beginning of the campaign few rural dwellers had any idea of what cholera was or how it was spread. Within a month some 600000 people were contacted at their homes and more read the messages that the university placed in local newspapers, taxis, and buses. Over 50000 primary school children were taught the basics of preventing cholera and of early treatment in a "child to community" scheme.

The campaign - "Not one more death from diarrhoea!"-also introduced an inexpensive and rapid diagnostic technique that identifies Vibrio cholerae. At the bedside of a person with suspected cholera a drop of faeces is placed in the well of a McArthur-style inverted slide and brought into focus at a magnification of $\times 400$ with a handheld plastic Eritrean public health programme microscope, based on the McArthur design. ${ }^{2}$ While the characteristic darting movement of the vibrio is observed a drop of diluted antiserum - the same as is used to identify cholera serotypes in agglutination tests - is added to the well. The immediate and dramatic inhibition of movement is pathognomonic of $V$ cholerae serotype 01 . With this technique cases were diagnosed in each of the seven regions of the state and later confirmed by conventional culture and biochemical examination.

Diagnosing and managing cholera do not require high tech or expensive solutions. They require the reorientation of thinking towards communities at risk.

N ANDERSSON A MORALES

Centro de Investigación de Enfermedades Tropicales,

Apdo 25A

Acapulco

Mexico

Roval Free Hospital School of Medicine,

London NW3 $2 \mathrm{PF}$

1 Dixon B. Basic science overlooked in fighting cholera. $B M \mathcal{F}$ 1992; 304:784. (21 March.)

2 Andersson N. Enter the barefoot microscopist. Joumal of Audiovisual Media in Medicine 1985;8:111-2.

\section{Work related disorders of the upper limb}

SIR,-J M Porter and colleagues' seem to have completely overlooked the important message in $\mathrm{N}$ $\mathrm{J}$ Barton and colleagues' paper on occupational causes of disorders in the upper limb.

So called "work related" disorders of the upper limb have been with us for many years, and with over 25 years' experience in occupational medicine I have seen my share of such cases, especially when I assessed "prescribed diseases" for the then Department of Health and Social Security. The apparent epidemic of work related musculoskeletal disorders may have resulted from irresponsible reporting of cases. There is no doubt that if the media report an influenza epidemic then every patient's sniff or cough is labelled influenzasimilarly, nearly every ache or pain in muscles is considered to be work related.

Barton and colleagues rightly condemned vague diagnoses such as repetitive strain injury. If I apply creosote to my greenhouse I develop aching muscles because I have undertaken an unusual task, but the condition resolves quickly and completely. An acute frictional tenosynovitis is well recognised and easily diagnosable and can be directly related to forceful, twisting and frequently repeated movements. I have yet to see a real case of acute frictional tenosynovitis resulting from keyboard work.

Acute frictional tenosynovitis commonly arose in agricultural workers working with sugar beet before sugar beet harvesters became commonplace. The combination of cold and wet conditions, the forceful repetitive movements, and the sudden seasonal introduction of the process contributed to this. The condition was indeed caused by the work process. Such is not the case with many other conditions well described by Barton and colleagues. A middle aged woman with osteoarthritic changes in the wrist joints may be predisposed to the carpal tunnel syndrome; work procedures may exacerbate this but do not cause it. An amateur footballer who returns to work after fracturing a tibia may experience pain in the leg because of prolonged standing at work, but the condition can hardly be described as work related.

I concur wholly with Barton and colleagues. The message is clear: it is vitally important to make a definite diagnosis in all of these cases at the earliest opportunity, when physical signs are present. We may have to identify and label a painful hand more accurately, based on actual pathological change. Only with such accuracy in diagnosis can we start correct treatment and consider the work conditions that might have to be modified. In the industries for which I work several tasks ought to result in musculoskeletal disorders but do not. This merely convinces me that the work is not the only factor that produces such disorders. The importance of ergonomic considerations is clear, but to embark on extensive and costly surveys of workplaces solely on the basis of possible work associated disease cannot be justified.

If we, as doctors, are unable to establish firm and specific diagnoses we would be prudent to abandon all terminology mentioning "work related" until further valid studies have indicated irrefutable aetiology.

Hunstanton,

Norfolk PE36 6DQ

I Porter JM, Buckle P, Robertson JC. Occupational causes of disorders in the upper limbs. BMF 1992;304:842-3. (28 March

2 Barton NJ, Hooper G, Noble J, Steel WM. Occupational causes of disorders in the upper limb. BMF 1992;304:309-11. (1 February.)

SIR, - In their review of occupational causes of disorders in the upper limb ${ }^{1} \mathrm{~N} J$ Barton and colleagues refer to a report by this school of manufacturing and mechanical engineering. ${ }^{2}$ I consider that the authors, by not correctly reporting the methods we used and by excluding the results of our analyses, seriously undervalue the importance of our work. I take issue with the statement that "the unsubstantiated assumption was made that because a symptom was present it was the work which had caused it."

In our study 256 subjects at 18 industrial sites were randomly selected from volunteers who reported themselves as injured or free of injury (designated as cases or controls, respectively). Each was physically examined, and a biomechanical analysis was made of work activities. Data on work organisation and personal data were also recorded. The physical examinations and work observations were made on site by two examiners, who were blind both to whether the subjects were cases or controls and to each other's findings. Tasks were then analysed to determine whether there was an anatomical link between the task and the subject's site of injury. If there was the task's biomechanical variables were analysed. This was also done for non-injured subjects to see whether the presence or absence of these factors could correlate with the injured or non-injured status.

The biomechanical variables together with organisational factors were subjected to a discriminant analysis, with injury as the dependent variable. Results showed that there was no significant association between injury and cycle time or overtime. Hand deviation and limb extension, force, and lack of job rotation were all significantly associated with injury $(p<0.0001)$.

I consider that these findings do not warrant the use of the term "unsubstantiated assumption," and I propose that identifying these work factors associated with injury can be vital to the successful design of work

In 1746 Ramazini wrote a treatise on: "The diseases of tradesmen, to which they are subject by their particular callings. With the method of avoiding and treating them." It is a sad reflection that so little progress has been made in the past 250 years on methods for preventing avoidable work related injuries.

DENNIS THOMPSON

Industrial Ergonomics Group

School of Manufacturing and Mechanical Engineering,

Birmingham University,

Birmingham B15 2TT

1 Barton NJ, Hooper G, Noble J, Steel WM. Occupational causes of diseases in the upper limb. BMF 1992;304:309-11. (1 February.)

2 Thompson D, Bacon PA, Harrington JM, Nayak USL. Occurrence and mechanism of occupational repetition strain injuries. Birmingham: School of Manufacturing and Mechanical Engineering, University of Birmingham, 1990

\section{Blood glucose and diabetic retinopathy}

SIR,-Olaf Brinchmann-Hansen and colleagues' study suggests that long term lowering of blood glucose concentration retards the progression of diabetic retinopathy. ${ }^{\prime}$ Multiple regression analysis of glycated haemoglobin $\left(\mathrm{HbA}_{1}\right)$ concentration and the progression of diabetic retinopathy showed the predictive value of a single measurement of $\mathrm{HbA}_{1}$.

We measured by radioimmunoassay the thromboxane $B_{2}$ and 6-ketoprostaglandin $F_{1 a}$ concentrations in platelet poor plasma from 55 diabetic patients (aged 11.6 (SD 1.6) years) and 33 controls (aged 10.5 (1.3) years). We calculated the ratio of thromboxane $B_{2}$ to 6-ketoprostaglandin $F_{1 \alpha}$ (normal value $<0 \cdot 5$ ). We divided the patients into four groups according to the duration of their diabetic disease. Early vascular lesions of diabetic retinopathy were sought by fluorescein angiography in 52 patients. Thirty one children did not have such lesions and 21 did.

The table shows our findings. By linear correlation we found positive correlations between $\mathrm{HbA}_{1}$ and thromboxane $\mathrm{B}_{2}$ concentrations $(r=0.58, \mathrm{p}<0.05)$ and the ratio of thromboxane $\mathrm{B}_{2}$ to 6-ketoprostaglandin $\mathrm{F}_{1 \alpha}(r=0.59, \mathrm{p}<0.001)$. There was a negative correlation between $\mathrm{HbA}_{1}$ and 6-ketoprostaglandin $F_{1 \alpha}$ concentrations $(r=-0.79, \mathrm{p}<0.01)$.

Our results suggest that the abnormality in the ratio of prostaglandins is a consequence not of the diabetic vascular lesion but of the poor diabetic

Ratio of thromboxane $B_{2}$ to 6-ketoprostaglandin $F_{l \alpha}$ concentrations and $H b A_{1}$ concentrations in children with diabetes and healthy children. Figures are means $(S D)$

\begin{tabular}{|c|c|c|c|}
\hline & $\begin{array}{l}\text { No of } \\
\text { patients }\end{array}$ & $\begin{array}{c}\text { Thromboxane } B_{2} \text { : } \\
\text { 6-ketoprostaglandin } \\
F_{1 \alpha}\end{array}$ & $\mathrm{HbA}_{1}(\%)$ \\
\hline All patients & 55 & $0.95(0.22)$ & $13 \cdot 25(2 \cdot 77)^{\star \star}$ \\
\hline \multicolumn{4}{|c|}{$\begin{array}{l}\text { Duration of } \\
\text { diabetes (years): }\end{array}$} \\
\hline$<1$ & 12 & $0.93(0.25)^{\star}$ & $12.88(4.06)^{\star \star}$ \\
\hline $1-5$ & 19 & $0.91(0.22)^{\star}$ & $13.05(2 \cdot 36)^{\star \star}$ \\
\hline $6-10$ & 15 & $1 \cdot 19(0.35)^{\star \star}$ & $14.34(2.83)^{\star \star}$ \\
\hline$>10$ & 9 & $0.79(0 \cdot 14)$ & $12.84(2 \cdot 26)^{\star \star}$ \\
\hline \multicolumn{4}{|l|}{$\begin{array}{l}\text { Fluorescein } \\
\text { angiography: }\end{array}$} \\
\hline $\begin{array}{l}\text { Positive } \\
\text { Negative }\end{array}$ & 21 & $0.87(0.36)^{\star}$ & $\begin{array}{l}13 \cdot 24(2 \cdot 51)^{\star \star} \\
13 \cdot 24(2 \cdot 59)^{\star \star}\end{array}$ \\
\hline $\begin{array}{l}\text { Negative } \\
\text { Controls }\end{array}$ & $\begin{array}{l}31 \\
33\end{array}$ & $\begin{array}{l}0.83(0.26)^{\star \star \star} \\
0.42(0.20)\end{array}$ & $\begin{array}{c}13.24(2.59)^{\star \star} \\
6.20(0.97)^{\star}\end{array}$ \\
\hline
\end{tabular}

${ }^{\star} \mathrm{p}<0.01,{ }^{\star \star} \mathrm{p}<0.001$ Compared with healthy controls. 
control. The indicators of prostaglandin metabolism are related to the $\mathrm{HbA}_{1}$ concentrations namely, to the different stages of diabetic control.

It is reasonable to suppose that the uncontrolled diabetic state and the shift in the balance of two antagonistic prostaglandins towards pathogenic direction might have a role in diabetic microangiopathy. Our observations support the authors' opinion.

L OROSZ M UDVARDY

Second Department of Medicine,

University Medical School

H-4012 Debrecen 12 ,

Hungary

A FEHER

$P$ VINCZE

L MADÁCSY

Second Department of Paediatrics,

Postgraduate Medical University,

Budapest,

Hungary

1 Brinchmann-Hansen O, Dahl-Jørgensen K, Sandvik L, Hanssen $\mathrm{KF}$. Blood glucose concentrations and progression of diabetic retionopathy: the seven year results of the Oslo study. $B M \mathcal{J}$ 1992;304:19-22. (4 January.)

2 Klein RK, Klein BEK, Moss SE, Davis MD, DeMets DL. Glycosylated haemoglobin predicts the incidence and progression of diabetic retinopathy. . $A M A$ 1988;260:2864-71.

\section{Treatment of hypertension in older adults}

SIR, - The recent report on the principal results of the Medical Research Council's trial of treatment of hypertension in older adults ${ }^{1}$ has led to a suggestion that hydrophilic and lipophilic $\beta$ blockers differ in terms of their cardioprotective effects. ${ }^{2}$ Such a suggestion deserves careful consideration in view of its widespread implications, if true.

Martin J Kendall invokes the literature on the long term use of $\beta$ blockers in secondary prevention as evidence for the hypothesis. ${ }^{2}$ This is indeed the most extensive and well documented source of controlled (and relevant) data. The original overview of the trials included over 20000 patients treated long term ${ }^{3}$; the updated analysis added two more trials, ${ }^{4}$ and to these should now be added the APSI trial,,$^{5}$ making a total of over 24000 patients.

The hydrophilicity of the $\beta$ blockers in these studies can be quantified by their distribution coefficients between octanol and aqueous buffer. ${ }^{67}$ Dividing the range of values of the distribution coefficients into equal and logical intervals on a logarithmic scale separated the $\beta$ blockers into four groups with similar degrees of hydrophilicity (see table) and had the added statistical advantage of dividing the clinical trials into four roughly equal sized groups in terms of total patient numbers. The apparent mortality benefit was calculated separately for each group of $\beta$ blockers over the relevant subset of trials using standard methodo-

No relation was immediately evident nor was it disclosed by more careful statistical testing either with a general test for heterogeneity ${ }^{3}\left(\chi_{3}^{2}=0.64\right.$, logy. ${ }^{3}$ The table shows the results.

$\mathrm{p}=0.89)$ or with a more specific test for trend in the odds ratio $\left(\chi^{2}=0.45, p=0.5\right)$. For each separate category of $\beta$ blockers there was a significant mortality benefit of a size consistent with the overall $22 \%$ reduction in mortality. More detailed analysis based on individual $\beta$ blockers led to the same conclusion.

Great care needs to be taken when assessing relations between the properties of individua $\beta$ blockers and their benefits. Even those thrown up by overviews themselves can be illusory. The original overview suggested that intrinsic sympathomimetic activity was an undesirable property based on mortality results ${ }^{3}$; subsequently analysis of non-fatal reinfarction and updating of the mortality data led one of the same authors to dismiss this finding. ${ }^{8}$

In terms of secondary prevention of mortality hydrophilic and lipophilic $\beta$ blockers seem to be equally cardioprotective.

Institute of Mathematics and Statistics,

J A LEWIS

University of Ken

Canterbury CT2 7N

1 Medical Research Council Working Party. MRC trial of treatment of hypertension in older adults: principal results. $B M$ 1992;304:405-12. (15 February.)

2 Kendall MJ. Treatment of hypertension in older adults. $B M J$ 1992; 304:639. (7 March.)

3 Yusuf S, Peto R, Lewis J, Collins R, Sleight P. Beta blockade during and after myocardial infarction: an overview of the randomised trials. Progress in Cardiovascular Diseases 1985;27:335-71.

4 ISIS-1 Collaborative Group. Randomised trial of intravenous atenolol among 16027 cases of suspected acute myocardial infarction: ISIS-1. Lancet 1986; ii: 57-66.

5 Boissel J-P, Leizorovicz A, Picolet H, Peyrieux J-C. Secondary prevention after high-risk acute myocardial infarction with
low-dose acebutolol. Am $f$ Cardiol 1990;66:251-60.

6 Cruickshank JM, Prichard BNC. Beta-blockers in clinical practice. Edinburgh: Churchill Livingstone, 1987:177.

7 Bax NDS, Lennard MS, Al-Asady S, Deacon CS, Tucker GT Woods HF. Inhibition of drug metabolism by $\beta$-adrenocepto antagonists. Drugs 1983;25(suppl 2):121-6.

8 Peto $R$. Why do we need systematic overviews of randomise trials? Statistics in Medicine 1987;6:233-40.

\section{Storing vaccines at the correct temperature}

SIR,-Yogini Thakker and Sheila Woods found that vaccines stored in community clinics and in general practice were exposed to temperatures that might reduce their potency. ${ }^{1}$ They concluded that adequate equipment and training for staff in maintaining the cold chain were essential for the success of an immunisation programme.

In Harrow I received a telephone call from a health visitor who was worried about the temperature of a particular general practitioner's refrigerator. Discussion with staff working in both general practice and community clinics showed that this was a fairly widespread problem.

I tackled the issue by producing a set of guidelines combined with a temperature char to record daily maximum and minimum temperatures. The chart was designed to be kept on or near each refrigerator in which vaccines were stored. Each clinic or surgery would designate a member of staff to be responsible for the

Hydrophilicity of $\beta$ blockers and its effect on long term mortality benefits after myocardial infarction

\begin{tabular}{|c|c|c|c|c|}
\hline $\begin{array}{l}\text { Distribution coefficient }\left(\mathrm{K}_{\mathrm{p}}\right) \text { in } o c t a n o l / \text { water } \\
\text { at } \mathrm{pH} 7 \cdot 4 \text { (range) }\end{array}$ & $\beta$ blockers & No of patients & Odds ratio & ( $95 \%$ confidence interval) \\
\hline $10 \cdot 0-100 \cdot 0$ & $\begin{array}{l}\text { Propranolol } \\
\text { Alprenolol }\end{array}$ & 6458 & 0.74 & $(0.63$ to 0.88$)$ \\
\hline $1 \cdot 0-10.0$ & $\begin{array}{l}\text { Timolol } \\
\text { Oxprenolol }\end{array}$ & 6314 & 0.77 & $(0.64$ to 0.92$)$ \\
\hline $0 \cdot 1-1 \cdot 0$ & $\begin{array}{l}\text { Pindolol } \\
\text { Acebutolol } \\
\text { Metoprolol }\end{array}$ & 6646 & 0.76 & $(0.63$ to 0.91$)$ \\
\hline $0 \cdot 01-0 \cdot 1$ & $\begin{array}{l}\text { Practolol } \\
\text { Atenolol } \\
\text { Sotalol }\end{array}$ & 5137 & 0.82 & $(0.68$ to 1.00$)$ \\
\hline
\end{tabular}

refrigerator and for record keeping. The guidelines on the chart give clear advice on how to care for the vaccines and refrigerator and what to do if something goes wrong or if advice is needed.

I approached Brent and Harrow Family Health Services Authority through its drug and therapeutics committee, and the idea was received enthusiastically. The chart has now been produced as an A3 size plastic laminated poster that can be wiped clean. It has been distributed, with a special pen, to all general practice surgeries and clinics in the area covered by Brent and Harrow Family Health Services Authority. It has been well received and has given rise to several inquiries about storing vaccines. I hope that it will make community staff more aware of the need to store vaccines correctly and will help to ensure that all vaccines retain their full potency until they are used.

I thank the members of the drug and therapeutics committee of Brent and Harrow Family Health Services Authority for their help and enthusiasm in funding the production of, and distributing, this chart.

Northwick Park Hospital,

PHILIPPA LEWIS

Harrow,

Middlesex HA1 3UJ

1 Thakker Y, Woods S. Storage of vaccines in the community; weak link in the cold chain? BMF 1992;304:756-8. (21 March.)

\section{Myeloma and benign intracranial hypertension}

SIR,-The report of $\mathbf{H}$ Wasan and colleagues on myeloma and benign intracranial hypertension provides insufficient data to justify their conclusions.' On the basis of the clinical history supplied, the diagnosis of benign intracranial hypertension in at least two of their cases is doubtful; few neurologists would accept dysphagia, dysarthria, psychomotor retardation, nystagmus, and unsteady gait as features compatible with this disease. No details of cerebrospinal fluid analysis are given, and there are no comments on computed tomographic appearances.

The authors have neglected to exclude the important possibility of dural sinus thrombosis, to which patients with myeloproliferative disorders are known to be susceptible. No mention is made in the report of investigations to elucidate such a diagnosis (contrast enhanced computed tomography, magnetic resonance imaging, or arteriography).

Finally, the authors' conclusion that all patients presenting with benign intracranial hypertension should be subjected to a myeloma screen, including bone marrow aspiration and trephine, is surprising. Most patients with benign intracranial hypertension are female; male patients with apparent benign intracranial hypertension should always be suspected of harbouring alternative pathology, particularly sinus thrombosis or diffuse meningeal tumour. Benign intracranial hypertension should therefore be a diagnosis of exclusion, especially in men, and bone marrow aspiration in typical female patients is not justified.

RICHARD J DAVENPORT ROGER E CULL

Neurology Clinic,

Royal Infirmary of Edinburgh,

Edinburgh EH3 9YW

Wasan H, Mansi JL, Benjamin S, Powles R, Cunningham D Myeloma and benign intracranial hypertension. BMF 1992 304:685. (14 March.)

AUTHOR'S REPLY, - We agree that dysphagia, dysarthria, and psychomotor retardation are atypical symptoms of benign intracranial hypertension. We do not attempt to attribute all symptoms to benign intracranial hypertension but have factually stated 